\title{
TEORIJA I PRAKSA POPLAVE NA DUNAVU KOD BUDIMPEŠTE
}

Janos Major $^{1}$

UDK: 627.51(439.151)

DOI:10.14415/konferencijaGFS 2016.066

Rezime: „Svaki put kada padne jača kiša Novi Sad ima problem sa atmosferskim vodama i poplavama. Sve se to povuče nakon pola sata, ali na momenat nastane haos." U Budimpešti je slična situacija, a na Budimskoj strani je još gore. U radu ćemo prikazati trenutnu situaciju sa svim geološkim osobinama i sa hidrotehničkim objektima koji čuvaju stanovništvo i grad. Na obali Dunava sagradjeno je $88,9 \mathrm{~km}$ dugačka glavna zaštitna linija od poplave. Na ovom ,kratkom delu” ima 84 potočića, 87 malih brana protiv poplave, 11 prepumpnih stanica na rekama, 246 drugih hidrotehničkih konstrukcija i šest termalnih banja na obali Dunava.

Mreža za sakupljanje otpadne vode ima više od $5400 \mathrm{~km}$ sa 194 prepumpnih stanica. Stručnjaci se trude da sakupljena iskustva koje su stekli naši prethodnici iskoriste za rešavanje najnovijih zadataka kod odbrane Budapešta od velikih voda koje proteku $u$ koritu Dunava.

Najavljeni su najnoviji projekti čiji je zadatak održavanje i poboljšavanje stanja nasipa $i$ zidova protiv poplave. U radu će se opisati moderni materijali i rešenja koje su trajno rě̌enje za stabilnost hidrotehničkih konstrukcija.

Ključne reči: poplave na Dunavu, flash flood, stabilnost hidrotehničkih konstrukcija, WSG aditiv.

\section{UVOD}

\section{Geomorfološke karakteristike}

Buda Hills igraju veliku ulogu na Budimskoj strani Dunava: Var-hegy, Gellért-hegy bili su strategijski važni objekti. Služili su i kao građevinski materijali sa drvećem, dolomitom, krečnjakom i peščanim kamenom.

Dunavske obale su obložene šljunkom koji ima metarske debljine i sadrži rezerve veoma kvalitetne pitke vode. Dunavska deonica koja proteče kroz Budapešt je 30 km dugačko i najviši deo je 640 m, i nalazi se kod južnog dela ostrva Sv. Andrije, Gellért-hegy ima 285 m. A još na vrh svega ima šest termalnih banja na obali Dunava. Na tektoničkoj liniji inače ima oko 120 komada termalnih izvora na teritoriji grada Budapešta.

Dunav kod Budapešta ima prosečan protok $2330 \mathrm{~m}^{3} / \mathrm{s}$, ako to uporedimo sa rekama Seine $500 \mathrm{~m}^{3} / \mathrm{s}$ i Rhine $2200 \mathrm{~m}^{3} / \mathrm{s}$ vidimo da je red veličine jednako.

\footnotetext{
${ }^{1}$ Prof. János Major MSc, PhD, Dr. Habil., University of Debrecen, Faculty of Engineering, Debrecen, WSG Ltd., Orosháza, Hungary, drmajorjanos@gmail.com
} 


\section{$4^{\text {th }}$}

INTERNATIONAL CONFERENCE

Contemporary achievements in civil engineering 22. April 2016. Subotica, SERBIA

Tehničke karakteristike sistema zaštite deonice Budapešt:

- 87 zaštitnih kapija od poplave (floodgate)

- 5400 km dugački sistem kanalizacije grada Budapešta

- 194 prepumpnih stanica na kanalizacionom sistemu

- 84 manjih reka i potočića

- ukupna dužina potočića je $168,5 \mathrm{~km}$

- 11 prepumpnih stanica na rekama

- 246 hidrotehničkih konstrukcija

- 6 termalnih banja na obali Dunava.

\section{VELIKE POPLAVE}

Kod velikih poplava [1] [4] najugroženije lokacije na obali Dunava su prikazane na Slici 1. U zadnje vreme su česte brze kiše posle kojih dolazi „flash-flood“ na ulicama, „ulice se pretvaraju u reke“. Na Budimskoj strani je situacija komplikovanija zbog toga što se atmosferske vode odvode zajedno sa komunalnom otpadnom vodom i kod određenog protoka prepuni kolektori se gravitaciono prazne u Dunav. U slučaju visokog vodostaja uključuju se prepumpne stanice (Slika 2. i Slika 3.).

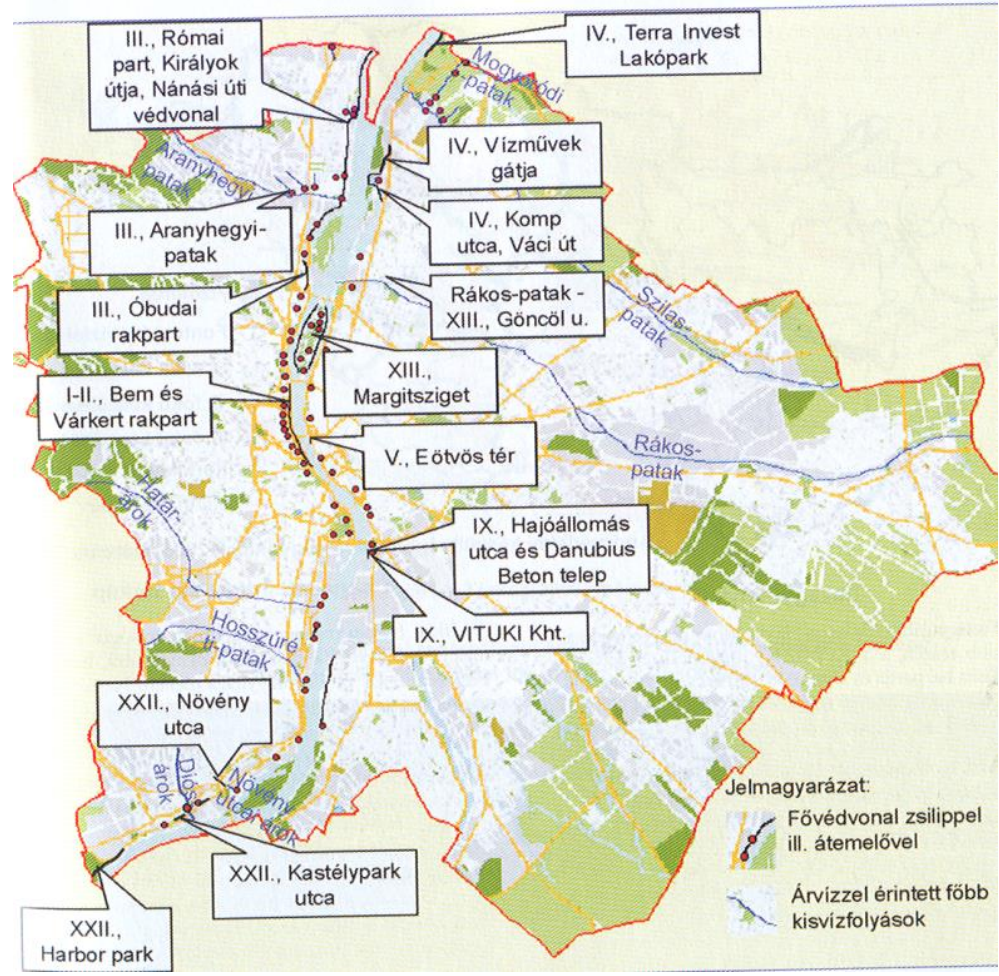

Slika 1. Lokacije intervencije u Budapeštu za vreme velikih voda 
4.

МЕЂУНАРОДНА КОНФЕРЕНЦИЈА

Савремена достигнућа у грађевинарству 22. април 2016. Суботица, СРБИЈА

Na Budimskoj strani u Fő ulici za vreme velikih kiša karakteristična situacija je sledeća:

- komunalni priključci su jako nisko uključeni u kolektore,

- to prouzrokuje da je razmera mešanja atmosferske: komunalne otpadne vode 3:1, priključci i kolektori biće poplavljeni,

- ometan protok prouzrokuje taloženje, izdvajanje masti, faktor-rizika da će podrumi biti poplavljeni raste, „, približava se neizdržljivom stanju”,

- na osnovu hidrauličkih ispitivanja možemo očekivati mnogo veće vodostaje i u glavnim kolektorima,

- za vreme velikih kiša očekivana razmera mešanje je 8:1.

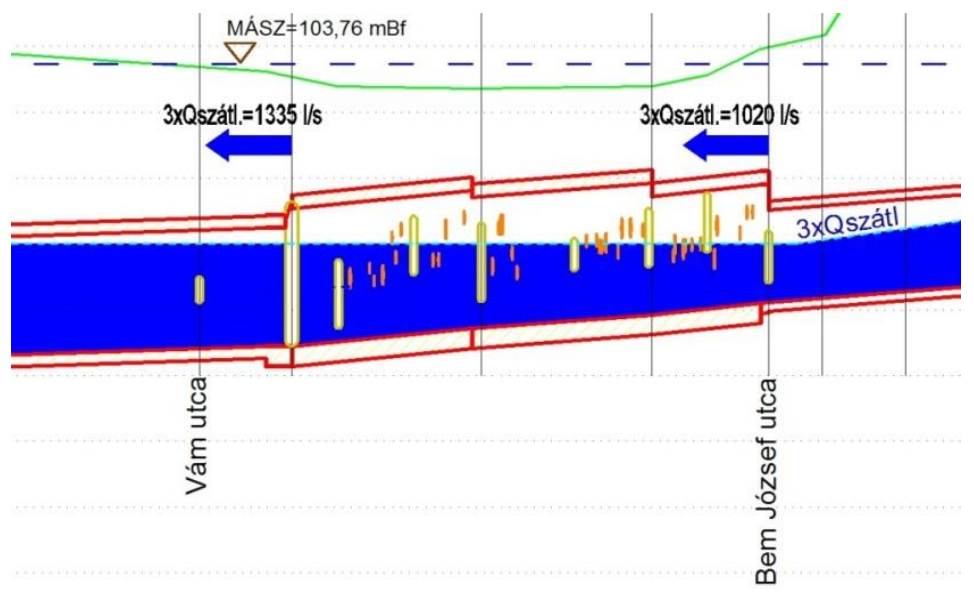

Slika 2. Produžni presek glavnog kolektora u Fö ulici sa priključcima

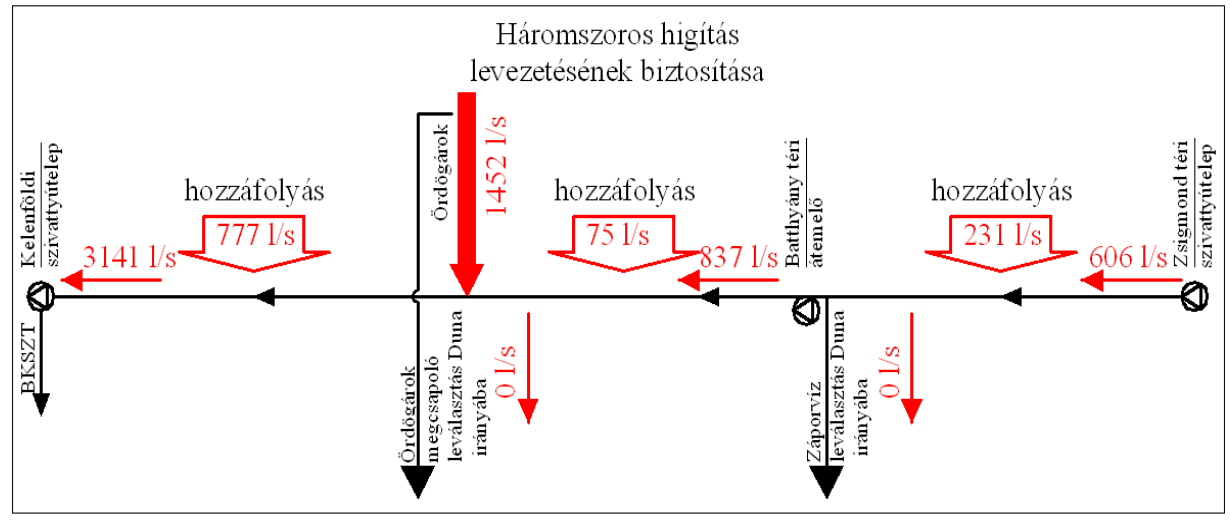

Slika 3. Hidraulički podaci za vreme 3:1 odnosa atmosferske i komunalne otpadne vode 


\section{$4^{\text {th }}$ inTERnATIONAL CONFERENCE}

Contemporary achievements in civil engineering 22. April 2016. Subotica, SERBIA

\section{MODERNE METODE ODBRANE OD POPLAVA}

Severni deo Budimske obale ugrožava život stanovnika [5] zbog šljunčane plaže, koja je jako vodopropusna i za vreme velikih voda na Dunavu, nema korisne metode koja bi bila efikasna u odbrani[2] [3].

Projektanti su smislili mobilne brane (Slika 4. i Slika 5.) samo za potpunu zaštitu potrebno je premestiti i vodovod i kanalizaciju iza brane [6].

Moguće rešenje je i injektiranje šljunčanog sloja, samo nije lako dostići potpunu vodonepropusnost, a drugi tehnički zadatak je kontrolisanje dostignute vodopropusnosti.

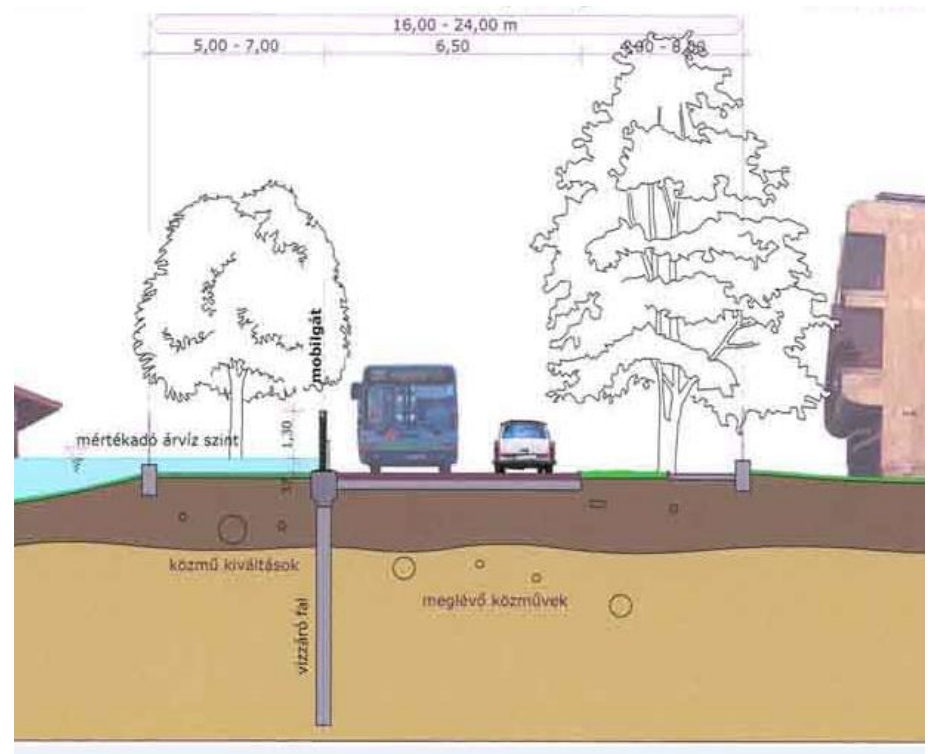

Slika 4. Lokalne barijere za zaštitu od poplave

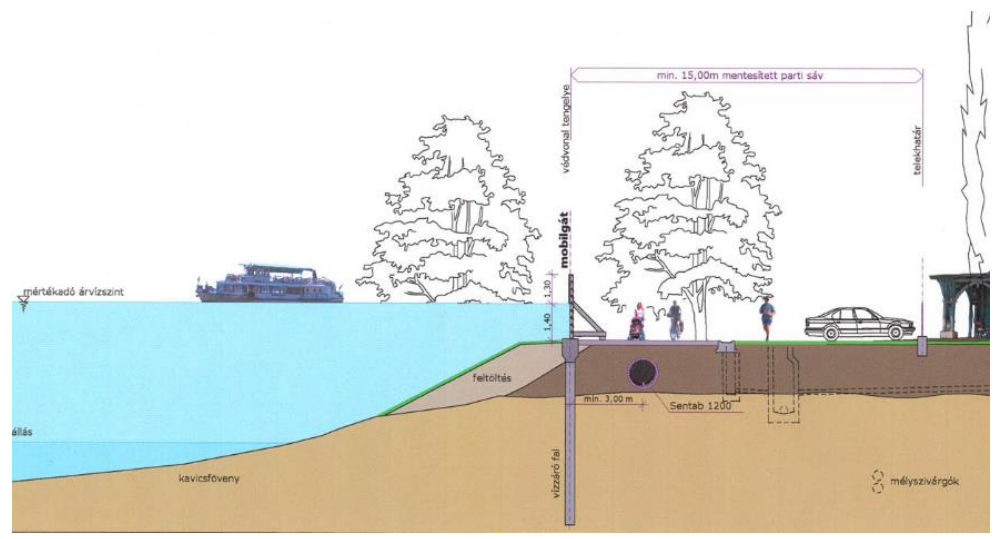

Slika 5. Rešenje odbrane od velikih voda sa montažnim branama velikih visina 


\section{MODERNE METODE ZA POBOLJŠAVANJE VODONEPROPUSNOSTI NASIPA}

U laboratorijama firme World Strong Guard Kft. (WSG Kft.) traju ispitivanja materijala WSG aditiva [7]. Taj materijal možemo koristiti kod hidrotehničkih konstrukcija za povećavanje vodonepropusnosti:

- kod nasipa protiv visokih voda-poplava (Slika 6.),

- kod intervencije za vreme odbrane od poplave (Slika 7. i Slika 8.),

- kod svih betonskih konstrukcija gde je vodonepropusnost zahtev,

- kod hidroizolacija korita zemljanih jezera,

- za intervencione svrhe u slučaju havarija na sistemu vodosnabdevanja,

- za intervencione svrhe u slučaju havarija na kanalizacionom sistemu.

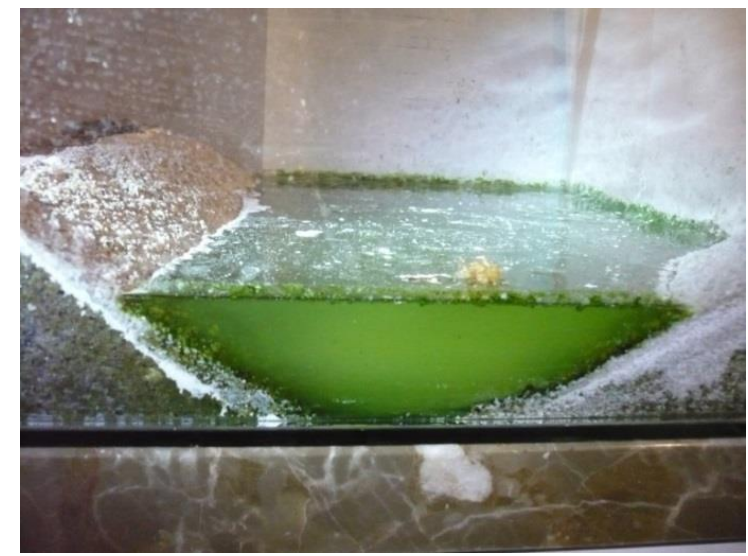

Slika 6. WSG aditiv osigurava za vreme poplave vodonepropusnost nasipa

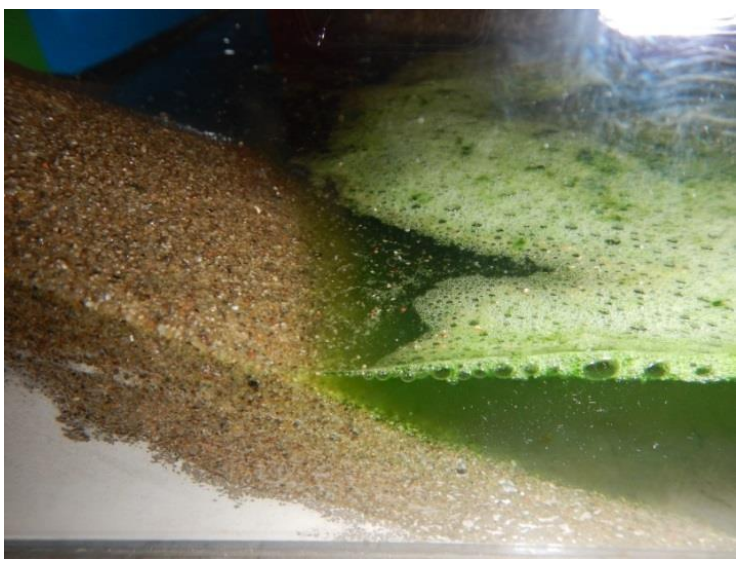

Slika 7. WSG aditiv je ugrađen ispod zaštitnog sloja nasipa 


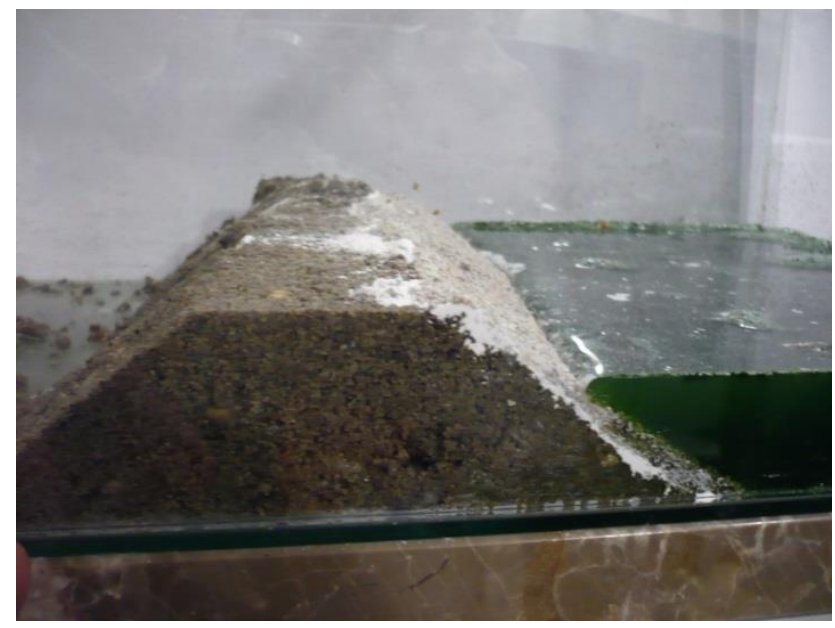

Slika 8. WSG aditiv je ugrađen na površini nasipa

\section{LITERATURA}

[1] János Major: Magyar Hidrológiai Társaság 31. Vándorgyülése, Gödöllö, 2013 http://www.hidrologia.hu/vandorgyules/31/dolgozatok/word/096_major_janos.pdf

[2] János Major: The water repellent treatment of building materials in thermal baths, Hydrophobe VII., International Conference, Lisbon, 2014

[3] János Major: WSG technology in the service of waterways and hydrotechnical engineering, World Canals Conference, Ghent,2015

[4] J. Major, L. Mrekva, G.Telekes: The 2006 Flood in Budapest, COST 2004-2009, Urban flood management, Bruxelles, 2007

[5] www.fcsm.hu

[6] Varga István Dr., A budai árvédelmi mobilgátrendszer tervezése, 2003

[7] WSG Kft.: http://www.worldstrongguard.hu, 2015

\section{FLOOD PROTECTION THEORY AND PRACTICE ON DANUBE DYKES IN BUDAPEST}

Summary: The paper shows the general characteristics of flood prevention in Budapest (Hungary) and region. The flood prevention division has to do with more than hundred crossing objects, groundwater, thermal springs.

Environmental protection problem is how to prevent the inappropriate discharge of waste water. 
4. МЕЂУНАРОДНА КОНФЕРЕНЦИЈА

Савремена достигнућа у грађевинарству 22. април 2016. Суботица, СРБИЈА

The paper describes impacts of flooding on city in August, 2015 in Budapest and edifications of flash flooding in Fö street.

In laboratories of World Strong Guard Ltd. is tested the WSG admixture permanently because the new fields of usage.

Keywords: WSG technology, durability of water utility structures, flood protection with WSG. 